\title{
Estimating the spatial distribution of high altitude wind energy potential in Southeast Europe
}

\author{
ARTICLE in ENERGY·AUGUST 2013 \\ Impact Factor: 4.84 · DOI: 10.1016/j.energy.2012.12.045
}

CITATIONS

8

4 AUTHORS, INCLUDING:

Marko Ban

University of Zagreb

26 PUBLICATIONS 61 CITATIONS

SEE PROFILE

Luka Perkovic

University of Zagreb

15 PUBLICATIONS 38 CITATIONS

SEE PROFILE

Neven Duic

University of Zagreb

394 PUBLICATIONS 1,437 CITATIONS

SEE PROFILE 


\title{
Estimating the spatial distribution of high altitude wind energy potential in Southeast Europe
}

\author{
Marko Ban ${ }^{\mathrm{a}, *}$, Luka Perkovića ${ }^{\mathrm{a}}$, Neven Duić ${ }^{\mathrm{a}}$, Ricardo Penedo ${ }^{\mathrm{b}}$ \\ ${ }^{a}$ Faculty of Mechanical Engineering and Naval Architecture, Ivana Lučića 5, 10000 Zagreb, Croatia \\ ${ }^{\mathrm{b}}$ Omnidea, Lda, Viseu, Portugal
}

\section{A R T I C L E I N F O}

\section{Article history:}

Received 31 August 2012

Received in revised form

30 November 2012

Accepted 1 December 2012

Available online 1 February 2013

\section{Keywords:}

High-altitude wind energy

Wind mapping

Energy systems

\begin{abstract}
A B S T R A C T
High altitude winds are considered to be, together with solar energy, the most promising renewable energy source in the future. Till date, there are no yet solutions available on the market but various concepts for utilizing high altitude winds are under research and are expected to be fully operational within next few years.

In this paper, the potential of high altitude wind energy will be investigated for the SEE (Southeast Europe) region and mapped using available data and technologies. The data available from NCEP/DOE analysis will be used in terms of obtaining the high altitude wind speeds for the span of 30 years, from 1980 to 2010, which are then processed for easier visualization. The obtained data is plotted against the available geographic data which could limit the positioning of the system (settlements, traffic...). The result of this work will display the "optimal" locations for these kinds of facilities for the Southeast Europe region. Such map could be beneficial for all future plans of utilizing this high altitude winds as a power source.
\end{abstract}

(c) 2013 Elsevier Ltd. All rights reserved.

\section{Introduction}

Due to the constant need for reduction of emissions and excessive dependency on oil, the research and development of renewable energy systems is the key factor in achieving the sustainable development of the world. Among solar and hydro, one of the most relevant renewable energy sources is wind. All commercial wind energy systems up to date are designed to utilize terrestrial winds, i.e. they are operating inside ABL (atmospheric boundary layer) up to heights of few hundred meters (for example, Enercon E-126 with rated capacity of $7.58 \mathrm{MW}$ has a total height of just above $198 \mathrm{~m}$ ). Such winds can also be highly intermittent in magnitude and direction, which depends on near- and farsurrounding influences, like air thermics, land cover and relief. In order to overcome these input uncertainties and to be able to correctly estimate available wind power potential, system designers are using long-term field measurements as the most reliable way for investigation of wind characteristics in ABL [1]. Study of Tieleman in 2008 [2] showed that the height of the neutral ABL is predicted to be above $1300 \mathrm{~m}$ for obstacle-free open terrain. Same study predicted that surface layer height is at least $200 \mathrm{~m}$ during

\footnotetext{
* Corresponding author. Tel.: +385 16168 494; fax: +385 16156940.

E-mail address: marko.ban@fsb.hr (M. Ban).
}

the strong-wind periods. This means that more persistent winds, both in magnitude and direction, occur above that height. High altitude wind systems are trying to utilize these winds. Currently none of the systems is yet on the market.

Bronstein in 2011 made a positive correlation between advancement in development of high altitude wind power systems to the price of oil [3]. Due to that fact, rapid development and positioning of the high altitude wind systems on the market are likely to occur. At this point there are numerous concepts designed for different altitudes. Lansdorp and Ockels in 2005 compared ladder mill and pumping mill concepts with two operating heights of 3 and $5 \mathrm{~km}$ [4]. Roberts et al., in 2007 presented a concept of tethered rotorcraft whose system performance is optimal at wind speeds of $10 \mathrm{~m} / \mathrm{s}$ (according to his data, those winds are occurring at approx. $4600 \mathrm{~m}$ ) [5]. Perković et al., in 2011 presented the concept based on Magnus' effect harvesting wind to top altitudes of $2000 \mathrm{~m}$ [6]. This concept is currently researched within the FP7-FET project called HAWE (high altitude wind energy), supported by European Commission [7]. High altitude kites are one of the prevailing concepts in the literature. Argatov et al., in 2011 presented analytical model of wind load on a tether constraining a power kite performing a fast crosswind motion $[8]$ with a maximal tether length of $800 \mathrm{~m}$. Previous analysis used by the same authors assumed length of tether cable to be $1260 \mathrm{~m}$ [9] and $1060 \mathrm{~m} \mathrm{[10].}$ Similar analysis is performed in thesis of Fagiano in 2009 [11] who 
stated that high-altitude wind energy systems using tethered air foils, like KiteGen concept, are able to exploit wind flows up to $1000 \mathrm{~m}$, by using 1200-1500 m long cables. DBR (dirigible based rotor) concept is able to operate to altitudes between 400 and $1000 \mathrm{ft}$ (130-330 m) [12].

The aim of this work is to give a fair estimation on available wind power in the region of SEE (Southeast Europe), both onshore and offshore (represented in Fig. 1), for heights above the current limits of conventional wind energy systems, with respect to the safety limitations of positioning ground station in the proximity of airports, populated regions, motorways and rail routes, as well as power lines. This region, named Western Balkans, was previously mapped including the potential of other, conventional types of renewable sources by Schneider et al. [13,14].

Archer and Caldeira in 2009 [15] assessed the worldwide available wind power for the first time using 28 years of satelliteprovided wind data by NCEP/DOE AMIP-II Reanalysis (Reanalysis2) database [16], estimating optimal heights for several largest cities in the world. The same source for wind data is used in this work. An overview of the dataset is given in Ref. [17]. The impact of satellite data on atmospheric analysis is given in Ref. [18]. Due to the expected technological, economical and legislative restrictions mainly related to ground control and airborne safety, top height of interest is set to $2500 \mathrm{~m}$. Wind power potential estimated in this work can be used as an input for determining position of ground station facilities in SEE region and sizing and designing future high altitude wind energy systems. Archer and Caldeira in their paper also gave wind potential estimates on certain specific urban areas around the world, but taking the safety precautions in consideration, urban areas are not appropriate for any kind of static airborne apparatus. It is the aim of this work to also point out this problem and to include this very important issue when determining the high altitude wind potential of a certain area.

An important aspect that should be taken into consideration when working with HAWE systems (high altitude wind energy) is safety of operation regarding the interaction with other devices that can potentially interact in the same airspace, like airplanes or other HAWE systems that experience failure if operating in a wind farm. Airspace can typically have 3 types of restrictions, Airport Terminal Control Areas and restricted areas that can be either manageable airspace or non-manageable airspace. The airspace is regulated generically at an international level by ICAO(International Civil Aviation Organization), and at a nation level by local entities. There is no specific legislation that deals with high altitude wind energy systems. The existing ICAO Annex 14 Chapter 6 covers obstacles to air traffic like buildings, power lines and wind turbines. In order to fulfill the ICAO Annex 14 requirements, the weight of warning systems would be too great for the systems because of the high altitudes of operation of HAWE systems. All HAWE systems that are known so far have the same generic components, namely,

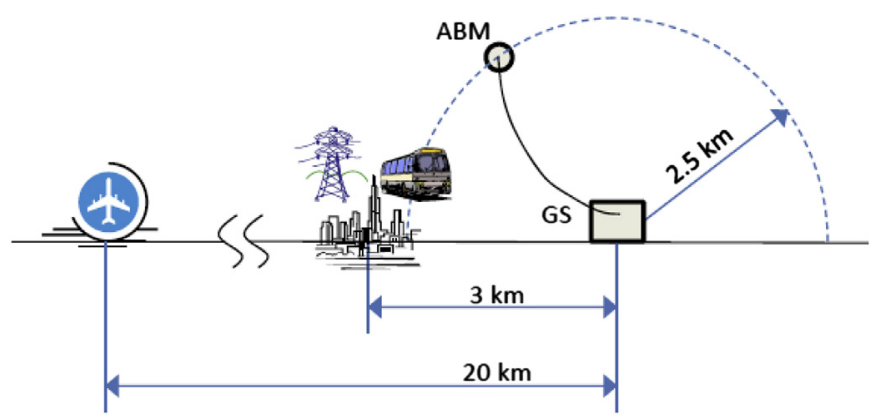

Fig. 1. Schematic view of the safety concept in the case of systems utilizing high altitude wind energy. an ABM (airborne module) linked by a cable to a GS (ground station).

Methodology used in this paper is presented first. It is followed by results and discussion. Finally, the conclusion is given regarding optimal locations and overall magnitude of wind power potential.

\section{Methodology}

The daily averaged high altitude wind data was extracted using the NCEP/DOE AMIP-II Reanalysis (Reanalysis-2) from Earth System Research Laboratory [16] for the year span between 1980 and 2010 and heights between 100 and $20,000 \mathrm{~m}$. Area of SEE lies between boundaries set by longitude $12.5^{\circ}-27.5^{\circ} \mathrm{E}$ and latitude $35^{\circ}-47.5^{\circ} \mathrm{N}$ and includes former Yugoslav republics Croatia, Slovenia, Bosnia and Herzegovina, Montenegro, Macedonia, Serbia, and Kosovo. Western Balkan countries of Greece and Albania are also included.

The data has been averaged and plotted in spatial chart with the wind power potential calculated using the equation for wind power density (with density $\rho$ and wind speed $\nu$ ):

$P=0.5 \rho|v|^{3} \quad\left[\mathrm{~W} / \mathrm{m}^{2}\right]$

Averaging is done over the height, available area and time span of 30 years. Top height for averaging is set to $2500 \mathrm{~m}$, since the authors' assumption is that systems utilizing high wind energy will not go above that value in near future. The average is calculated by using the following expression:

$P_{\mathrm{av}}=1 / A \int_{A}\left[1 / \tau \int_{\tau}\left(1 / H \int_{H} P(h) \mathrm{d} h\right) \mathrm{d} t\right] \mathrm{d} a \quad\left[\mathrm{~W} / \mathrm{m}^{2}\right]$

where $H$ represents top height for averaging, $\tau$ represents time span for averaging and $A$ is available area for positioning the system.

For determining possible locations for systems utilizing the high altitude wind energy, the concept of such systems should be considered. All known concepts are having ABM (airborne module) tethered to the GS (ground station), like the ones with rotating balloons or kites mentioned in the Chapter 1. Safe locations for GS facilities are determined as the ones that are not representing possible danger to civil structures in the scenario when the cylinder is crashed down. It is still unknown what would be the commercially viable size of the ABM's but the assumption is that it might be large enough to cause significant damage if crash scenario occurs. The concept of safety is presented in Fig. 1.

Principally, the cable length can be as great as $4600 \mathrm{~m}$ [5]. The authors believe that HAWE systems could operate in zones of restricted airspace. To warn any air traffic that might potentially violate the restricted airspace in which HAWE systems operate, it should have lights and markers for operational altitudes of up to $500 \mathrm{~m}$. Such systems should ensure detection in all directions. Above $500 \mathrm{~m}$, in addition to the previously mentioned items, all the HAWE systems must also include a transponder.

As for the safety on the ground two modes of failure must be considered, the Airborne Module and the cable. If a fatal ABM failure occurs the ABM will still be attach to the cable and in the worst case scenario the radius of influence will be the tether length. Concepts lighter than air will have the advantage of taking longer to reach the ground. If it is the cable that fails, systems that have propellers or blades in the ABM might still land safely, if storage energy is available. Such concepts might drift away to a radius of influence higher than the tether length if self-destruction systems are not implemented or if they are not self-propelled. In all concepts the cable would fall in an uncontrollable way so that the minimum radius of influence will again be the cable length. For a cable failure the minimum distance that a high altitude wind 
energy system should be from roads, railroads, power lines and houses is the maximum tether length.

Regarding airports, ICAO Annex 14 chapter 6 guidelines stated a $10 \mathrm{~km}$ radius where very high obstacles cannot be in the same patch as the approach to the runways and in that radius all high obstacles must be extremely well marked and lighted. Additionally for airports with a dedicated control center a conservative estimative is a radius of $50 \mathrm{~km}$ taking into consideration the Airport Terminal Control Areas, where they have full control overall air traffic from $3410 \mathrm{~m}$ to the ground. Since the majority of airports in the investigated area are smaller in size, a general $20 \mathrm{~km}$ safety radius has been imposed to all.

For wind farms all the systems would be aligned in the same wind direction and because of the cable failure mode the minimum distance between consecutive systems would once again be the maximum tether length.

In order to ensure the safety of the areas surrounding the facility several layers have been considered:

- Transport, including

$\bigcirc$ Roads (high speed roads have been traced from the viaMichelin map [19] - assumption was made that, in case of apparatus crashing on regional roads, the slower traffic should not be affected)

$\bigcirc$ Railways - the data was traced using the OpenStreetMap [20]

Airports - location data was extracted for the region from Global Airport Database [21]

- Settlements - location data extracted and filtered from National Geospatial-Intelligence Agency's GNS files [22], since the database provides only the locations, but not the population of each settlement, the assumption that larger settlements are usually crossings of major road and railway routes, as well as having a nearby airport, the population data was not used to extend the boundaries - a simple $3 \mathrm{~km}$ radius was considered around the location provided by the database

- Power lines - the data was traced using available imagery from the countries electric companies or other sources, such as Global Energy Network Institute [23], or Energy in Central and Eastern Europe [24]

The above location data was used to overlay all the layers showing areas where, considering mentioned safety, the facilities should not be used. For the airports, a $6 \mathrm{~km}$ radius was used while for all other layers a $3 \mathrm{~km}$ radius was plotted (if the selected height of the apparatus is selected to be no higher than $2.5 \mathrm{~km}$ ). For offshore regions no limitations were provided.

An additional layer was used to filter out all areas higher than $1.8 \mathrm{~km}$ which would, in the case of the mentioned selected production height become unfeasible to run the facility. The height data was obtained from ASTER-GDEM satellite imagery [25], averaged to a $100 \mathrm{~m}$ square region and overlaid on the existing result.

The final result for possible locations is obtained by overlaying all the above restrictions and subtracting the results from the power potential image, thus leaving visible the available potential for harvesting the high altitude winds.

Additionally, per-month analysis of the high altitude winds in the area was performed showing that the variations between months are below $25 \%$ as seen in Fig. 2, which also additionally supports the concept. Intermittency is present as it is with the conventional low altitude wind harvesting, and it can be dealt with by including the facility with some appropriate type of energy storage $[15,26,27]$ highly beneficial for possible $100 \%$ renewable systems in the future $[28,29]$.

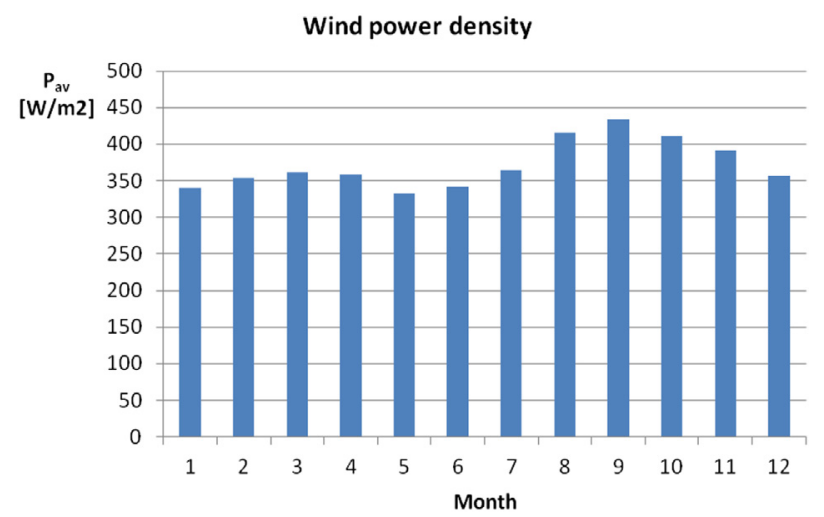

Fig. 2. Wind power density averaged by month over the 30 -year time span, to the height of $2500 \mathrm{~m}$ and over the available region.

\section{Results and discussion}

Results showing separate layers, which are limiting the positioning the GS by criteria stated in Chapter 2, are presented in Fig. 3 . It can be seen that the most limitating layer in terms of available area is settlements. Also, regions of elevations higher than $1.8 \mathrm{~km}$ are significant.

All layers combined are presented in Fig. 4a. Fig. 4b shows available area for positioning GS based on the criteria stated in Chapter 2.

Fig. 5 shows wind power density on altitude of $2.5 \mathrm{~km}$ plotted over the area available for positioning the GS in the region of SEE. It can be seen that highest values of wind power density are offshore, with increasing tendency towards the south, between Italy and Greece. Due to the high density of settlements, onshore positions are very dispersed and covering low area. At the same time, they have lower wind power density available for power production. Among onshore locations, north-east regions (eastern Slovenia, Croatia and Serbia, together with AP Vojvodina) as well as locations on Peloponesis, Greece, are the best for positioning GS's for high altitude wind power production due to the high energy potential, mainly above $250 \mathrm{~W} / \mathrm{m}^{2}$. All other regions of SEE are having moderate potential between 200 and $250 \mathrm{~W} / \mathrm{m}^{2}$.

Wind power density averaged by month and up to the height of $2500 \mathrm{~m}$ is showing great potential for producing power from high winds in region of SEE. Variations are under $25 \%$, based on minimal $\left(333 \mathrm{~W} / \mathrm{m}^{2}\right)$ and maximal $\left(454 \mathrm{~W} / \mathrm{m}^{2}\right)$ value.

The average over the entire 30-year span, to the top height of $2500 \mathrm{~m}$ and over the available region is $371 \mathrm{~W} / \mathrm{m}$ [2]. From Fig. 5 it is clear that offshore area is main contributor to such high average.

Even if the above results suggest the offshore as optimal positions for HAWE systems, there are also significant restrictions. There are commercial ports and routes coming to and from those ports. Even though there are no fixed "roads" at sea ships follow certain routes. Because the time of response of ships is much slower than other objects, such as airplanes in the air and cars on the ground, the requirement for the safe operation distance is higher with the authors considering that 5 times the maximum length of the tether being a good value. This would mean that if the tether has a length of $2.5 \mathrm{~km}$ then the required distance would be $12.5 \mathrm{~km}$. On the other hand, the airborne module and the cable would sink due to their weight and in most cases would not represent a great threat even when directly colliding with shipping routes. At sea the requirements to alert the air traffic would remain the same with the requirements in the sea bed being increased with light beacons being located from 3 to 5 times the maximum operational cable 
(a)

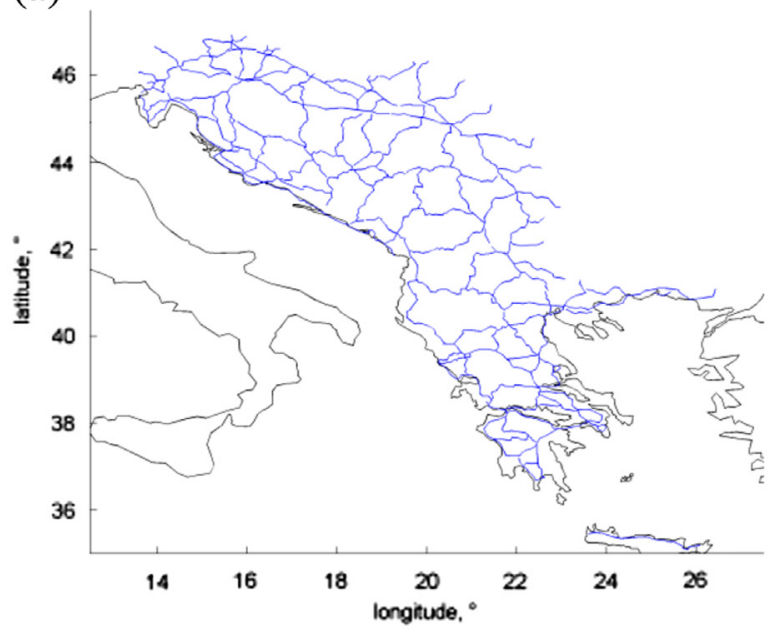

(c)

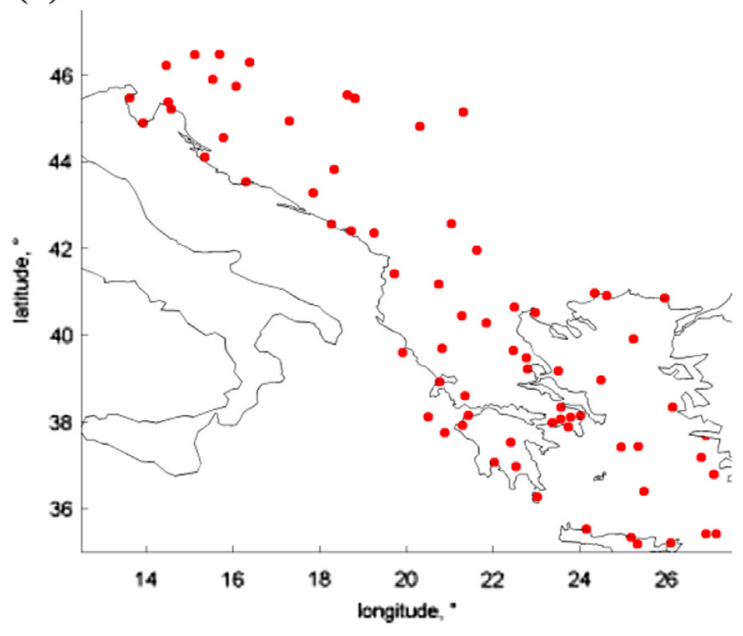

(e)

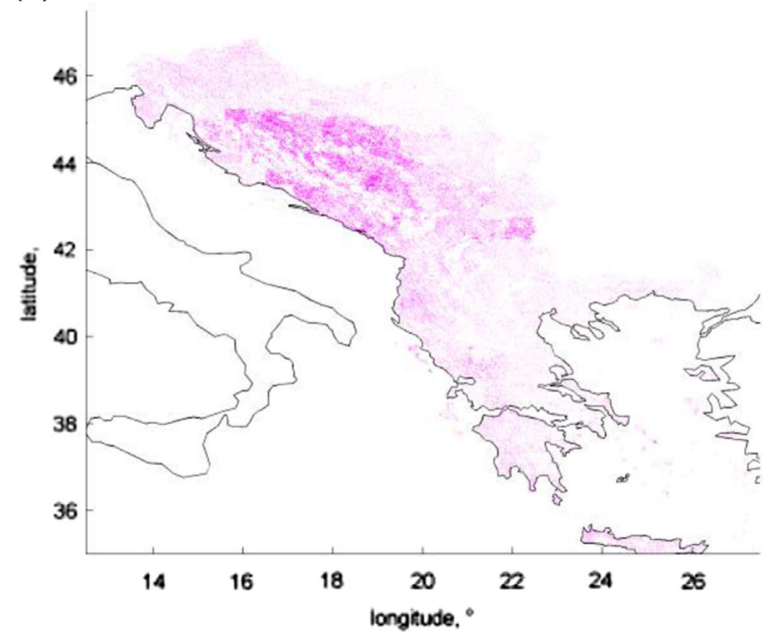

(b)

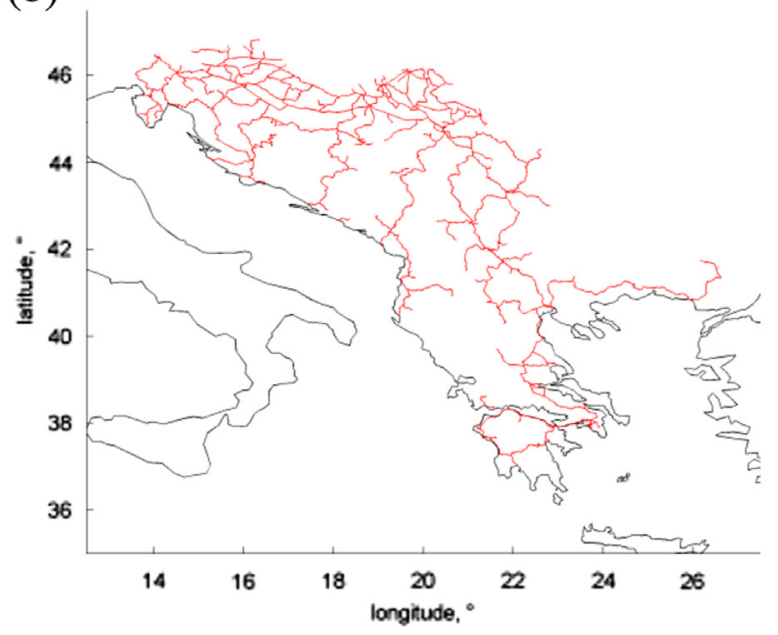

(d)

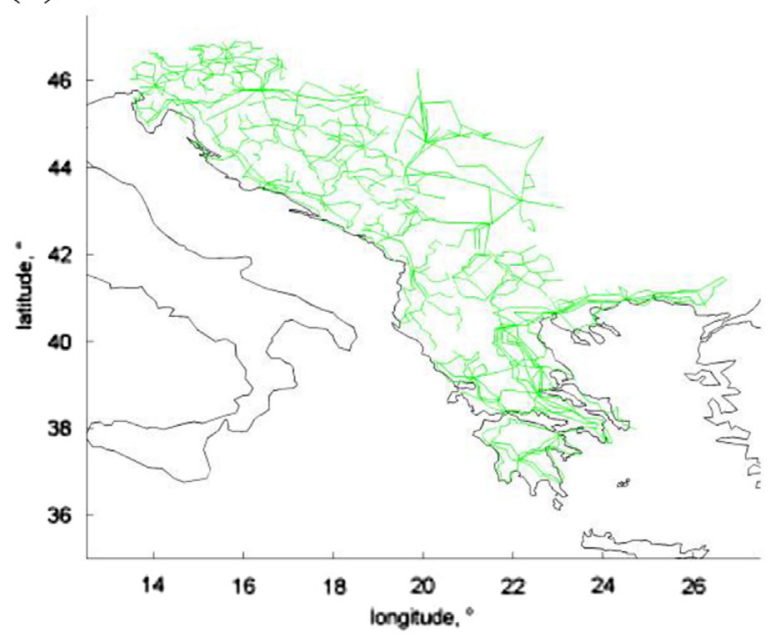

(f)

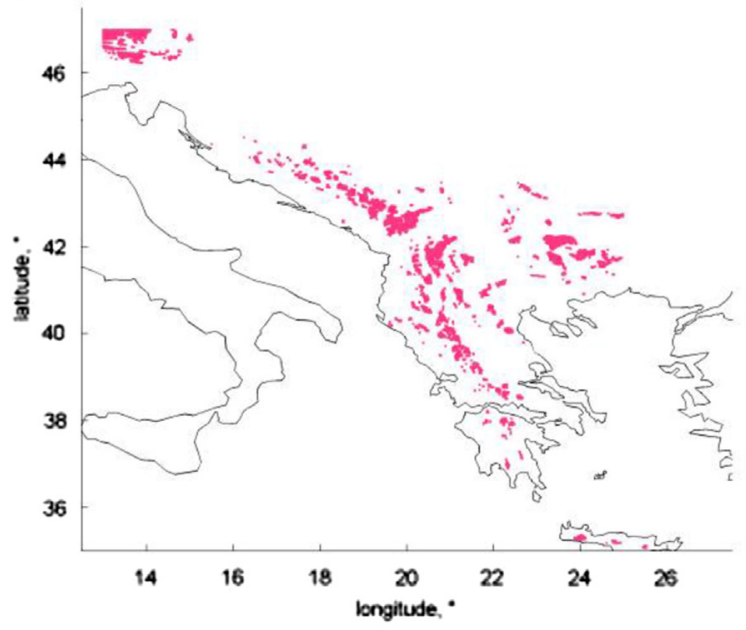

Fig. 3. Layers over the SEE region representing: roads (a), railroads (b), airports (c), power lines (d), settlements (e) and elevations (f). 
(a)

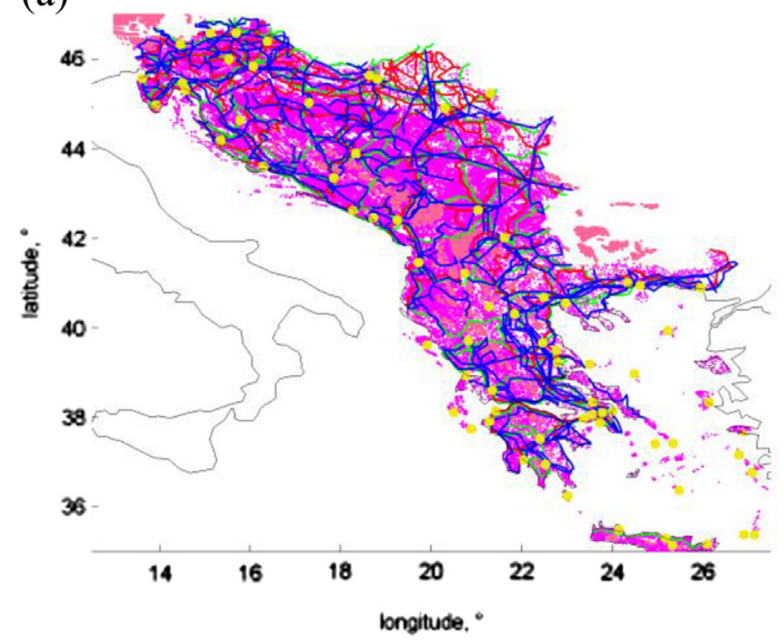

(b)

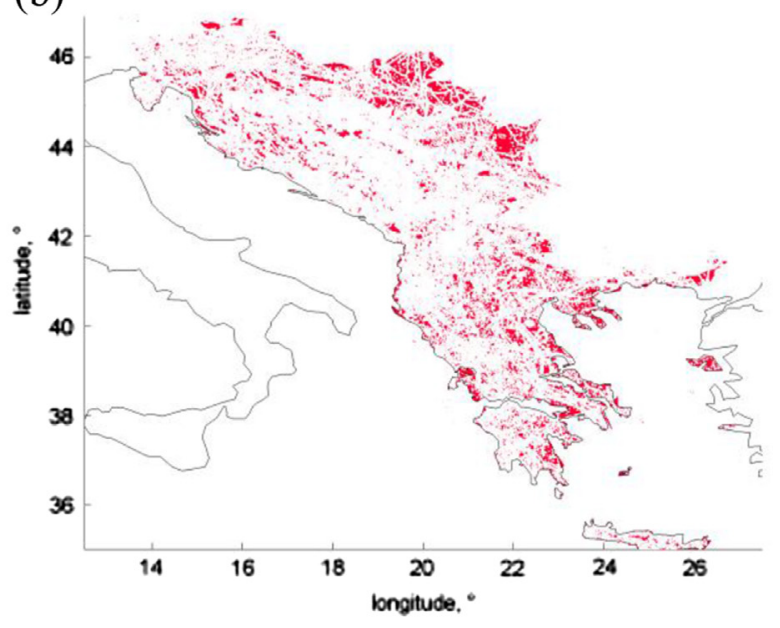

Fig. 4. All layers combined over the SEE region (a) and resulting area available for placement of ground station (b).

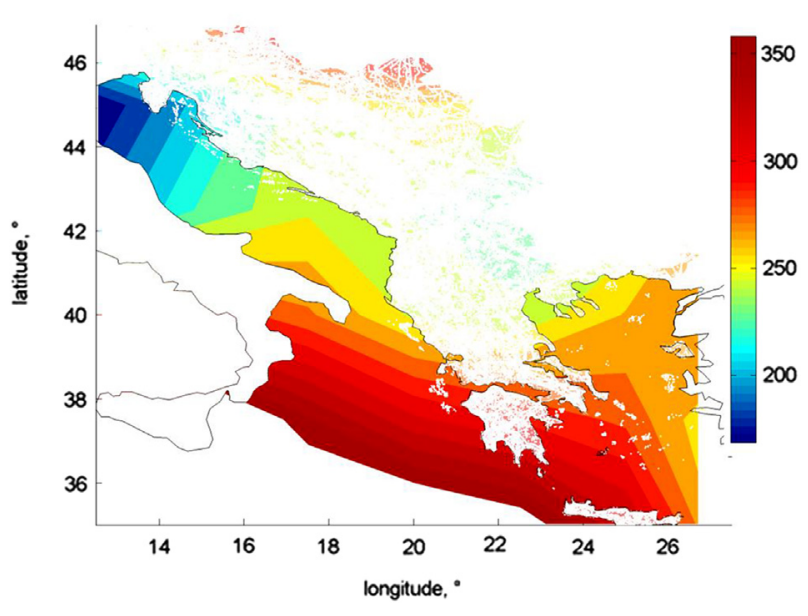

Fig. 5. Spatial distribution of wind power density over the SEE region. The color bar represents wind power density.

length and ensuring visibility from all directions. Because of the large area that this work covered and an irregular nature of shipping routes, these have not been considered in detail, but left for possible future work investigating a potential for a single country.

Possible problems with seclusion of the off-shore facilities and transmission of the produced energy to land could be circumvented by incorporating an appropriate type of energy storage, as discussed in previous chapter (e.g. hydrogen production).

\section{Conclusion}

This work shows that high altitude wind energy has very high potential, even if the top operating height is estimated only to $2500 \mathrm{~m}$ (with a number of concepts suggesting substantially higher altitudes). Nevertheless, onshore area available for positioning GS's is highly dispersed and potential is unevenly distributed through SEE region, as represented by Fig. 5. Per-month average analysis, Fig. 2, shows that variations between months are below $25 \%$, which is also significant information for incorporating high-altitude wind systems into future energy planning of the SEE.

For future investigations, separation of onshore and offshore data should be taken into account due to the different investment and technological approaches for these two categories. Future investigations could also go in the direction of finding optimal tether cable length for high-altitude wind systems, since there are two opposing consequences with respect to that parameter. In other words, using greater heights for harvesting would, even with greater power potential, will lead to significantly lower amount of available regions for GS facilities (especially considering the settlement layer).

Refinements and advancement in limiting data should also be taken into account. These are:

- Detailed road data (available also from OpenStreetMaps)

- Population data for settlements (possibly available through the national census data)

- National parks data

- Other special areas (mined fields)

\section{Acknowledgments}

This work has been done with the support of Omnidea Lda, Portugal, who originally developed the concept. The concept is now under the research within the project High Altitude Wind Energy (acronym HAWE), with the financial support of EC's Seventh Framework Programme (RCN 96067). NCEP_Reanalysis 2 data was provided by the NOAA/OAR/ESRL PSD, Boulder, Colorado, USA, from their Web site at www.esrl.noaa.gov/psd/.

\section{References}

[1] Li QS, Zhi L, Hu F. Boundary layer wind structure from observations on a 325 $\mathrm{m}$ tower. Journal of Wind Engineering and Industrial Aerodynamics 2010. 98(12):818-32.

[2] Tieleman HW. Strong wind observations in the atmospheric surface layer. Journal of Wind Engineering and Industrial Aerodynamics 2008;96(1):41-77.

[3] Bronstein MG. Harnessing rivers of wind: a technology and policy assessment of high altitude wind power in the US. Technological Forecasting and Social Change 2011;78(4):736-46.

[4] Lansdorp B, Ockels WJ. Comparison of concepts for high-altitude wind energy: 2005.

[5] Roberts BW, Shepard DH, Caldeira K, Cannon ME, Eccles DG, Grenier AJ, et al. Harnessing high-altitude wind power. IEEE Transactions of Energy Conversion 2007;22(1).

[6] Perković L, Silva P, Ban M, Kranjčević N, Duić N. Harvesting high altitude wind energy for power production: the concept based on Magnus' effect. Applied Energy 2012;101:151-60.

[7] European Comission Community Research and Development Information Service (CORDIS). [Internet]. [cited 2012 Aug 23]. Available from: http:// cordis.europa.eu/projects/rcn/96067_en.html. 
[8] Argatov I, Rautakorpi P, Silvennoinen R. Apparent wind load effects on the tether of a kite power generation. Journal of Wind Engineering and Industrial Aerodynamics 2011;99(10):1079-88.

[9] Argatov I, Rautakorpi P, Silvennoinen R. Estimation of the mechanical energy output of the kite wind generator. Renewable Energy 2009;34:1525-32.

[10] Argatov I, Silvennoinen R. Energy conversion efficiency of the pumping kite wind generator. Renewable Energy 2010;35(5):1052-60.

[11] Fagiano L. Control of tethered airfoils for high-altitude wind energy generation; 2009.

[12] Magenn Power Inc. [Internet]. [cited 2012 Apr 12]. Available from: http:// www.magenn.com/technology.php.

[13] Schneider DR, Duić N, Bogdan Ž, Marko B, Grubor B. Mapping the potential for decentralised energy generation based on RES in Western Balkans. Thermal Science 2007;3(11):7-26.

[14] Schneider DR, Neven D, Bogdan Ž. Mapping the potential for decentralized energy generation based on renewable energy sources in the Republic of Croatia. Energy 2007;9(32):1731-44.

[15] Archer CL, Caldeira K. Global assessment of high-altitude wind power. Energies 2009;2(2):307-19.

[16] Earth system research laboratory. [Internet]. [cited 2012 Apr 12]. Available from: www.esrl.noaa.gov/psd/.

[17] An overview of Reanalysis-2. [Internet]. [cited 2012 Apr 12]. Available from: www.cpc.ncep noaa gov/products/wesley/reanalysis2/kana/reanl2-1.html.

[18] Kanamitsu M, Ebisuzaki W, Woollen J, Yang SK, Hnilo JJ, Fiorino M, et al. NCEPDEO AMIP-II reanalysis (R-2). Bulletin of the American Meteorological Society 2002;83(11):1631-43.
[19] ViaMichelin. [Internet]. [cited 2012 Apr 12]. Available from: http://www. viamichelin.com.

[20] GEOFABRIK. [Internet]. [cited 2012 Apr 12]. Available from: http://downloadint.geofabrik.de/readme.html.

[21] The global airport database. [Internet]. [cited 2012 Apr 12]. Available from: http://www.partow.net/miscellaneous/airportdatabase.

[22] National Geospatial-Intelligence Agency. [Internet]. [cited 2012 Apr 12]. Available from: http://earth-info.nga.mil/gns/html/namefiles.htm.

[23] Global Energy Network Institute. [Internet]. [cited 2012 Apr 12]. Available from: http://www.geni.org/index.html.

[24] Energy in Central and Eastern Europe. [Internet]. [cited 2012 Apr 12]. Available from: www.enercee.net.

[25] ASTER-GDEM. [Internet]. [cited 2012 Apr 12]. Available from: www.gdem. aster.ersdac.or.jp.

[26] Lund H. Large-scale integration of wind power into different energy systems. Energy 2005;30(13):2402-12.

[27] Hedegaard K, Mathiesen B, Lund $\mathrm{H}$, Heiselberg P. Wind power integration using individual heat pumps - analysis of different heat storage options. Energy 2012;47(1):284-93.

[28] Krajačić G, Duić N, Zmijarević Z, Mathiesen B, Anić Vučinić A, MdG C. Planning for a $100 \%$ independent energy system based on smart energy storage for integration of renewables and $\mathrm{CO}_{2}$ emissions reduction. Applied Thermal Engineering 2011;31(13):2073-83.

[29] Mathiesen B, Lund H, Karlsson K. 100\% Renewable energy systems, climate mitigation and economic growth. Applied Energy 2011;88(2): 488-501. 